\title{
RPA Vendor Evaluation and Selection using AHP and Kano Model
}

\author{
Aishwarya Banerjee', Shilpa Parkhi ${ }^{*}$ \\ 1,2 Symbiosis Institute of Operations Management, Nashik, Symbiosis International (Deemed University), Pune, India
}

\begin{abstract}
Robotic Process Automation (RPA) as a technology has gained momentum due to the onset of Industry 4.0. RPA is considered to be the simplest forms of automation in which, typically, the human actions are mimicked without taking into account the complex judgements associated with it. Hence, RPA is deemed fit for the rule-based tasks which are highly repetitive, bulky and are errorprone. Traditionally, organizations looking to increase its operations efficiency improve workforce utilisation, turn to RPA. With the shift in working pattern enforced by COVID-19, RPA adoption is no more a luxury, but a necessity. In a short span of time, the number of RPA vendors, that is the developers and providers of RPA software have significantly increased and due to current demands of RPA, it is expected to grow further. This increase in choices makes the vendor selection part of any RPA Implementation Project highly complex and confusing. Keeping in mind the significance of the vendor selection process, various methods of RPA Vendor Selection have been previously proposed but it is still evolving along with the changing needs of the Businesses. This Research paper aims to propose a standard model using Kano Model and Analytic Hierarch Process (AHP) such that it can be customized during each new RPA implementation project without compromising on the basic structure and method for evaluation.
\end{abstract}

Keywords:

Robotic Process Automation(RPA), RPA Vendor Selection, Analytic Hierarchy Process(AHP), Kano Model

Article Received: 10 August 2020, Revised: 25 October 2020, Accepted: 18 November 2020

\section{Introduction}

RPA is a boon of Industry 4.0 and it is a "relatively new phenomenon as it started getting traction at the end of 2014"(Noppen, 2019). RPA is "driving much of the long-tail process automations that were previously impossible to achieve"(Gould, 2018). Further, the COVID-19 outbreak has made it a necessity. According to the IDC survey "Wide recognition of the value of digital transformation and information technology among all employees" (Xie, 2020) is one of the top positive impacts of the pandemic and nearly " $65 \%$ of industrial users have formulated plans for working from home"(Xie, 2020) due to the outbreak. "RPA uses software to automate tasks previously performed by humans that use rules to process structured data to produce deterministic outcomes. It automates the repetitive, largely physical, clerical tasks typical of much office work."(Willcocks, 2020) Further it has been confirmed that for "tasks that are largely driven by rules, schedules, or events, a robot can take the wheel and get the job done."(Scheppler \& Weber, 2020). As discussed in the report by(Gurwitz, 2020) "For companies wrestling with the challenges of COVID-19, RPA offers wideranging benefits. Every organization has clerical, time-consuming tasks that demand accuracy and speed, but don't require decision-making to accomplish." Hence RPA is the most common form of automation that companies are quickly adopting and "its (RPA) successful implementation across various sectors during COVID-19 has embarked on the upsurge in its future demands undeniably"'(Srivastava, 2020).

According to (Bygstad, 2017) RPA is an example of "lightweight IT" because "it's deployment is frequently done by users or vendors, bypassing the IT departments". Thus, with the upsurge in demand, the RPA ecosystem is bound to change drastically as the main entities of this ecosystem are the "RPA tech providers, RPA implementation partners, RPA marketplaces and RPA innovators" (AIMultiple, 2020). RPA technology providers are the developers of software bots and RPA Applications. RPA implementation partners use of these RPA apps to develop process automation solutions for companies. RPA marketplace is hub of reusable RPA solutions. Reusability has the benefits like "Reduction in implementation time, reduction in programming effort, process improvement and reduced maintenance cost" thus a repository of such reusable solution are created. "These reusable solutions are provided in marketplaces built by leading RPA companies"(AIMultiple, 2020). Lastly, RPA 
innovators are the companies that are currently engaged in building future breakthroughs like the no-code or self-learning RPA tools.

The purpose of RPA ecosystem is enhancing the quality, variety, availability and utility of the RPA solutions keeping up with the demand and innovation. Considering that RPA adoption will create demand and RPA consultants play an important part in manipulation and determining the patterns in these demands, we can re-define the RPA ecosystem with three broad entities - (1) RPA vendors (collective group of RPA solution providers, implementation partners, marketplace and innovators), (2) RPA adopters (companies that implement RPA solutions), and (3) RPA Consultants (the facilitators of strategy, advice and expertise for the implementation projects).

While implementing RPA, companies need to go through the RPA vendor selection process. The pace at which RPA vendors are increasing in numbers in remarkable. The Forrester report by (Le Clair et al., 2017) itself counted 38 RPA product vendors excluding the professional service firms that delivered RPA. The count has increased in last three years to more than 50 and is expected to plummet post COVID-19. This will add to the dilemma of the RPA adopters. Despite the dilemma, the vendor selection process should never be bypassed.

In this research, traditional vendor/supplier selection methods used typically in manufacturing industry will be compared with RPA or other technology vendor selection. Existing methods and guidelines as established by research papers and articles of Consulting firms will be analysed. With the inspiration drawn from the Kano Model and the existing methodologies, a new model for RPA Vendor Evaluation and Selection will be designed which will be customer-centric, flexible and more accurate.

\section{Literature Review}

Vendor Evaluation, also known as "Supplier Evaluation", includes activities to "identify, evaluate and contract" suppliers (Taherdoost \& Brard, 2019). For conventional industries like manufacturing, the objective is "to reduce purchase risk, maximize overall value to the purchaser, and develop closeness and long-term relationships between buyers and suppliers" (Taherdoost \& Brard, 2019). It is also necessary for staying relevant in the market and attaining supply chain superiority. The two major issues that are to be taken care of while developing an effective vendor/supplier evaluation and selection model are - "evaluation criteria and the method to be used".(Firat et al., 2017). Both of these have been discussed in detail.

\subsection{Evaluation Criteria}

A list of 23 criteria by(Dickson, 1966) known as the Dickson's vendor selection criteria were laid down. These criteria were reviewed during another research and it was found that " 47 of the 74 articles (that is $64 \%$ of the articles that were reviewed) discussed more than one criteria and that in one article, 18 criteria are discussed."(Weber et al., 1991). Ideally, "the nature of the item to be purchased has a major influence on the factors that are considered when selecting a supplier"(Dickson, 1966). RPA vendor, which sells a software or technology is different from a supplier of physical goods. Thus, the evaluation factors will be different. Nevertheless, it cannot be ignored that some factors like "Quality, Price, delivery(reliability), Technical Capability, Warranties”(Dickson, 1966) are important irrespective of the nature of item. These have been classified as factors of "extreme and considerable importance"(Dickson, 1966).

"Despite the existence of a large number of RPA vendors and products in the market, there remains much hyperbole around what RPA represents for organisations" (Syed et al., 2020) because the amount of research needed to establish models and frameworks around this does not exist. Clearly, "academic research in the area has only recently begun to rise."(Syed et al., 2020) The importance of the RPA vendor evaluation and selection for an RPA implementation project has been discussed by reputed consulting firms like MBB (McKinsey \& Company, Boston Consulting Group, Bain \& Company) and the Big 4 (PwC, Deloitte, KPMG and E\&Y). Some have even come out with their versions of analysis or methodology to select vendors. However, most of these consultants have a tie-up with certain RPA vendors and "may not always provide unbiased information."(Syed et al., 2020)

Most of these articles state the factors to be considered without diving into the methodology. PwC (Chambers et al., 2017) has classified the 
parameters based on "Scalability requirement, security concerns and others generic parameters". (Naved Rashid, Cathy Tornbohm, 2020) from Gartner has laid down 8 evaluation criteria for vendors, they are "RPA Platform Architecture, hosting options, Developer Experience, Business Rules and Process Orchestration, Integration and API, Administration and Security, Resilience and DR (Disaster Recovery), and AI Augmentation". It further gives reference to (Ray et al., 2020)help adopters narrow down their choices based on the visual placement of the RPA Product vendors into four quadrants named as "Challengers, Leaders, Niche Players and Visionaries" based on their "Ability to execute" and "Completeness of Vision". The Forrester report by (Le Clair et al., 2017) has evaluated 12 vendors on " 28 criteria grouped into 3 - high level bucket: Current Offering, Strategy and Market presence." Forrester came up with these criteria after evaluating the Strength and Weaknesses of the top RPA vendors. Despite the fact that PwC (Chambers et al., 2017) pointed out that "One size never fits all" and that an Organization must avoid "blindly selecting an RPA tool" following their close competitor, most of the papers and corporate reports that were studied have either pre-mapped the existing RPA vendors into certain categories that create a bias. Others have provided a generic approach to select the vendors which are helpful but may not be holistic for a particular Organization.

In reality, the criteria can vary according to situation, industry, business type, business goals and many other factors. Thus, here we have focused more on what to go with the selected evaluation criteria rather than stating any hard and fast criteria. For this we have taken reference of the Kano Model.

\subsubsection{Kano Model}

Named after its pioneer Noriaki Kano, the Kano Model is a Quality Function Deployment (QFD) tool which "helps in setting direction and priorities for addressing customer needs" (Asif, 2015). According to the Kano model, there are three types of customer needs that can be mapped out on a coordinate system of $y$-axis representing 'customer satisfaction' and $\mathrm{x}$-axis representing 'provision of product/service attributes' respectively. Based on that, the products or services can be said to have most and the least impact on customers. Hence Kano Model can be used to identify the "spoken" and "unspoken" customer expectations.(Frrat et al., 2017). "Spoken" expectations are the ones which the customer openly and directly states as wants. Level of presence of these spoken expectations proportionally affects the level of fulfilment. "Unspoken" wants are classified as "Attractive" and "Must-be". "Must-be requirements are untold expectations, and if they are not delivered, this will lead to extreme dissatisfaction of customers and can result in complaints. However, if they are delivered, customers will only be in a state of 'not dissatisfied. Attractive requirements are the ones that the customers do not expect from the design essentially. If they are not delivered, the customers will not be dissatisfied. However, if they are delivered, customer satisfaction will be increased substantially"(Matzler et al., 1996).

Precisely, there are the following five categories as given below in which the "Kano Quality model classifies the attributes of a product"(Sunil Kumar \& Routroy, 2017) -

1. Must-be attributes

2. One-dimensional attributes

3. Attractive attributes

4. Indifferent attributes

5. Reverse attributes

In our study, we intend to use these attributes to categorise the criteria of satisfaction of customers (RPA adopters) during RPA vendor evaluation. However, let us what these categories of product features originally signify.

1. Must-be attributes: Expected to be present and the absence extremely dissatisfies the customer.

2. One-dimensional attributes: The attributes linearly correlated with customer satisfaction. The more it is present, the more it satisfies the customer.

3. Attractive attributes: These are the unexpected attributes which delights the customer if present, but does not disappoint them if absent.

4. Indifferent attributes: The attributes which the customers are indifferent to, that is their presence or absence does not matter.

5. Reverse attributes: The attributes if present causes customer dissatisfaction 
The same has been represented in a graph in Routroy, 2017). figure 1 as referenced from (Sunil Kumar \&

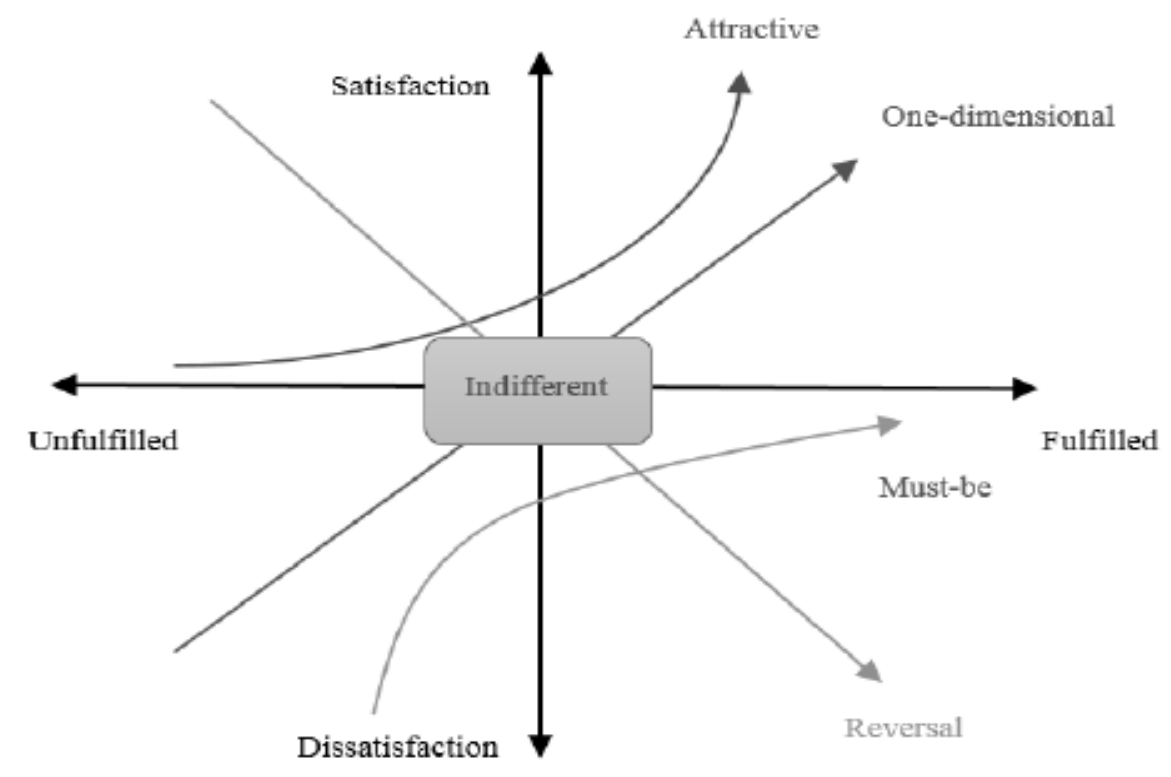

Figure 1 - Kano's two-dimensional quality model(Sunil Kumar \& Routroy, 2017)

Although, traditionally Kano Model was a tool for various Product developers to understand the various product attributes that the customers perceive to be important, owing to the versatility of the tool it was extended to be used in the service industry. A study showed that refined Kano Model could "generate different classification of quality attributes for the pharmaceutical logistics industry".(Chen et al., 2020). Using Kano Model could give insights to "Hong Kong Express to identify their service areas that needed to be improved and paid attention to increase customers' satisfaction in future" (Wong \& Ho, 2019) "Kano model can be deployed to identify a wide range of complex patient needs and convey its potential usefulness in the continuous improvement of the healthcare sector.'(Materla et al., 2019). It has also proven effective to identify "how different after-sales services quality elements affect customer satisfaction"(Shokouhyar et al., 2020).

\subsection{Evaluation Method}

There also exists a gap when it comes to a proper established quantitative model like the ones which exist in the case of supplier evaluation for the manufacturing industry. Hence, in this paper established MADM (Multi-Attribute Decision Making) models are identified by studying the existing literature as "In past years, the multiattribute decision-making (MADM) approaches have been extensively applied by researchers to the supplier evaluation and selection problem"(Ghorabaee et al., 2017). To ensure that we select only the approaches popularly used, the paper by(Ghorabaee et al., 2017) was referenced which states that "AHP and TOPSIS methods are the most popular approaches" based on the study of papers from "339 publications including papers in peer-reviewed journals and reputable conferences and also some book chapters over the period of 2001 to 2016.". Even according to (Ho et al., 2010) "the most popular integrated approach is AHP-GP" as "there are seven (8.97\%) out of 78 journal articles proposing AHP to deal with the supplier selection problem" based on analysis of research papers during the time between 2000 to 2008. Also, AHP has previously been successfully used in combination of a number of methods(Büyüközkan, 2012) (Ivlev et al., 2014) (Improta et al., 2019) (Singh et al., 2020). Thus, for our paper, we have selected the AHP model.

\section{The Analytic Hierarchy Process (AHP)}

The Analytic Hierarchy Process or popularly known as AHP as introduced by Thomas L. Saaty in 1980 is "an effective tool for dealing with complex decision making"(Chen et al., 2020) and it helps the decision maker in setting priorities and making the best choice. In case of RPA vendor evaluation and selection, owing to the complex RPA ecosystem as discussed in the introduction, 
with a large number of growing vendors offering a variety of services in their RPA software package, setting the priorities and making the right decision is important. AHP being a mathematical model "provides a hierarchical representation that enables analytic decision-making" and is quite versatile in the fields of both qualitative and quantitative analysis.(Firat et al., 2017). "The AHP method is flexible and allows development stakeholders to assign a priority (relative weight) to each factor through pairwise comparison"(Pesonen et al., 2001) "In AHP analysis, participatory consultation with stakeholders is an initial step for constructing indicators critical for attaining the overall goal and deciding on their corresponding weights"(Baffoe, 2019). Hence, in our case it is necessary that the stakeholders, that is the RPA adopters participate by giving preference scores to the different available options so that the goal of selecting the best fitting RPA vendor can be attained.

Analytic Hierarchy Process is carried out using following steps (Baffoe, 2019) -

1. Determining the goal and the associated options (criteria, alternatives, etc.) on which decisions need to be made.
2. Give preference score to each options based on the Saatys 9-points scale (Refer Table 1) and construct a Pairwise Comparison Matrix.

3. Determine the consistency index $(\mathrm{CI})$ as follows: $C I=(\lambda \max -n) /(n-1)$, where $n$ refers to the size of matrix that depends on the number of options you are comparing. $\lambda \max$ is the average of the weighted sum/priority ratio of each of the alternatives.

4. Next the consistency is checked. Consistency ratio $(\mathrm{CR})$, is referred to the ratio $\mathrm{CI} / \mathrm{RI}$, in which $\mathrm{RI}$ is the Random Index (see Table 2). The RI essentially depends on the number of alternatives being compared. The CR is the measure of the "consistency of judgments" and is expected to be less than or equal to 0.10 . A greater value than this indicates inconsistencies which will prompt us to reassign the scores and repeat the steps.

5. Finally, the relative weights of the individual indicators are aggregated to generate a "vector of composite weights" for each of the alternatives and rank them accordingly.

\begin{tabular}{|c|l|}
\hline Value of $a_{j k}$ & \multicolumn{1}{c|}{ Interpretation } \\
\hline 1 & $j$ and $k$ are equally important \\
\hline 3 & $j$ is slightly more important than $k$ \\
\hline 5 & $j$ is more important than $k$ \\
\hline 7 & $j$ is strongly more important than $k$ \\
\hline 9 & $j$ is absolutely more important than $k$ \\
\hline
\end{tabular}

Table 1-Saatys scale of relative scores

\begin{tabular}{|c|c|c|c|c|c|c|c|c|c|}
\hline$m$ & 2 & 3 & 4 & 5 & 6 & 7 & 8 & 9 & 10 \\
\hline$R I$ & 0 & 0.58 & 0.90 & 1.12 & 1.24 & 1.32 & 1.41 & 1.45 & 1.51 \\
\hline
\end{tabular}

Table 2-RI values based on number of criteria ' $\mathrm{m}$ '

\section{Methodology}

The research can be spread out in the following steps -

1.) Model Creation

- Model Overview

- Model Assumptions

- Model Development for criteria categorization
- Model Development for calculation of scores

2.) Model Demonstration

- Establish a premise for demonstration (Scenario)

- Criteria selected based on literature from recent corporate research and reports 
- Demonstration of the calculation of vendor score

\subsection{Model Creation}

Our proposed model has been inspired from the Kano Model and the AHP method, the former is for selecting, segregating, and deciding priorities qualitatively, and the latter is to do the quantitative weight assignment and relative scoring to build the model for calculation of RPA vendor scores and solve the underlying purpose of RPA vendor selection based on the score. The creation of equivalent model has been logically explained under the following 3 subheadings -

1. Model Overview

2. Model Assumptions

3. Model Development for criteria categorization

4. Model Development for calculation of scores

\subsubsection{Model Overview}

For both, Kano Model and AHP, the common ground is the criteria prioritization. Using the reference from the pre-defined categories of Kano
Model as discussed in section 2.3, we will be creating customised categories for the requirements of the RPA adopters.

Then, analysing the offerings of shortlisted $R P A$ vendors for this evaluation process, we will categorize their offerings into these customdefined categories. Although the name and essence of the categories will remain same, every new RPA adopter will be given a chance to adjust the priority scores of these categories. This is how the model will be standard, yet customizable according to specific business needs. Apart from this, the features under each category will be given priority scores by the RPA adopters. Also, the number of features in each category will be taken into account during the scoring along with the feature and category priority scores.

It is important to understand that we are trying to standardize the system of RPA vendor evaluation without compromising on the customisability of the model based on the diverse and unique needs of the business. The steps to be followed according to this model is given in Figure 2 which will be further explained in the upcoming sections. However, before explaining the new categories and detailed working, it is important to state the assumptions.

\begin{tabular}{|c|c|}
\hline 1 & Identify required features based on process analysis \\
\hline & $\downarrow$ \\
\hline 2 & $\begin{array}{l}\text { Categorize features and assign comparative score to categories to } \\
\text { determine priority score }(\mathrm{Cg}, \mathrm{Ci}, \mathrm{Cp}, \mathrm{Cd})\end{array}$ \\
\hline & $\downarrow$ \\
\hline 3 & $\begin{array}{l}\text { Assign comparative weight to each feature to get priority score of features } \\
\text { category-wise }(\mathrm{Gj}, \mathrm{l}, \mathrm{j}, \mathrm{Pj}, \mathrm{Dj})\end{array}$ \\
\hline & $\downarrow$ \\
\hline 4 & $\begin{array}{l}\text { Match the features offered by each of the identified RPA vendor into the } \\
\text { categories and count them (Ngj,Nij,Npj,Ndj) }\end{array}$ \\
\hline & $\downarrow$ \\
\hline 5 & $\begin{array}{l}\text { Multiply matched feature counts with category priority score to get Revised } \\
\text { Category Priority Score for vendors ( } \mathrm{Rg} \mathrm{j}=\mathrm{Ngi} \times \mathrm{Cg} \text { ) }\end{array}$ \\
\hline 6 & $\begin{array}{l}\text { Find the average priority score per category based on matching features for } \\
\qquad \text { each vendor (Agj,Aij,Apj,Adj) }\end{array}$ \\
\hline 7 & $\begin{array}{l}\text { Multiply the revised category priority score with the average category } \\
\text { priority score for the vendor to get category final score Fgj,Fij,Fpj,Fdj }\end{array}$ \\
\hline 8 & $\begin{array}{l}\text { Final Vendor Score is calculated as the sum of Final Scores of all categories } \\
\qquad \text { for a vendor. } V j=F g j+F i j+F p j+F d j\end{array}$ \\
\hline
\end{tabular}

Figure 2 - Steps for calculating the vendor scores based on proposed model 


\subsubsection{Model Assumptions}

Following assumptions are to be considered:

- The RPA adopters are sufficiently aware of the features they need either on their own or via consultation.

- They can easily segregate the identified features into categories suggested in the model

- An initial shortlisting of RPA vendors already done

- RPA adopters can categorise the unconsidered features that are discovered only during Vendor analysis as per our model

\subsubsection{Model Development for Criteria Categorisation}

The new attributes have been designed based on the scenarios as explained below and also illustrated in the mapping diagram (figure 3).

Scenario 1: Features that are pre-determined by the RPA adopter

In this scenario, the categories are Game Changers and Influencers where they can be mapped directly with Must-be attributes and Onedimensional attributes respectively.

- Game changers (G): These are the features RPA adopters are actively seeking for in the RPA solution. Their presence is expected and their absence will be a potential deal-breaker. Hence, the name game changers. This category has the maximum weightage.

- Influencers (I): These RPA features are again expected by the RPA adopters and the degree to which they are present in a RPA solution, determines the attraction towards the RPA vendor being selected. This category has a significant amount of positive weight.

Scenario 2: Features unknown to the RPA adopters

In this scenario the newer features that were previously not considered by the RPA adopter can be mapped to two categories Persuaders and Dissuaders which are quite similar to the Attractive and Reverse attributes of the Kano Model.

- Persuaders (P): These are the features that the RPA adopters did not consider, but they will be delighted if they get these. These features are perceived as an added advantage and can compel the RPA adopter to consider the vendor. This category has a positive weightage depending upon the level of positive impact it creates.

- Dissuaders (D): The presence of these features is perceived as a disadvantage. So, its presence in an RPA offering dissuades the RPA adopter from selecting that particular vendor. The weightage of this category is directly converted to its negative equivalent consider the dissuading effect.

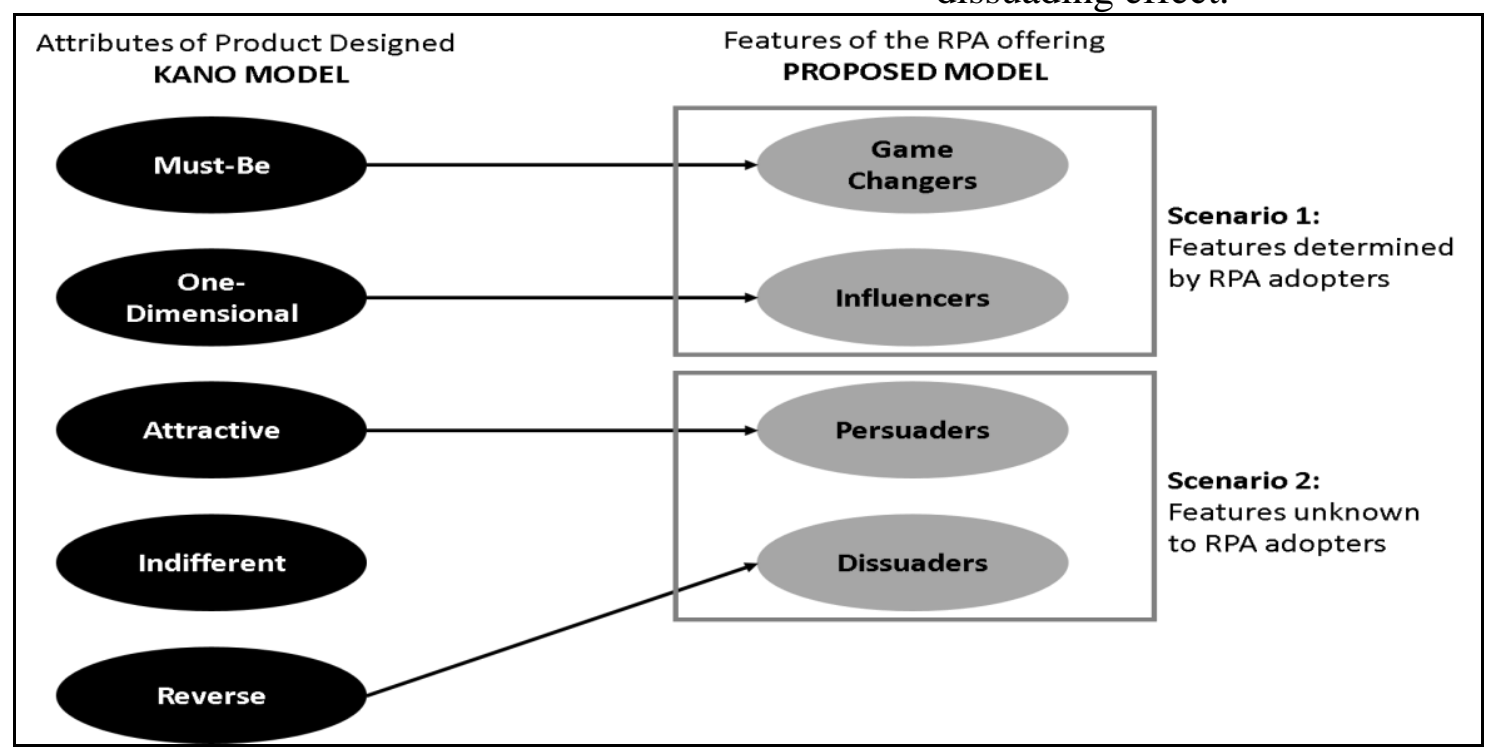

Figure 3 - Mapping of Proposed Model based on the Kano Model 


\subsubsection{Proposed Model for Calculation}

Figure 3 shows the steps to be carried out for calculation of final vendor scores of the selected RPA vendors. In figure 3, step 2 to 8 gives a detailed process for the calculation based on the category priority score, feature priority score, as well as the number of features in a given category. Once the Step 1 of feature identification is complete,

Step 2: Categorize the features and assign score to the categories. $\mathbf{C g}, \mathbf{C i}, \mathbf{C p}$ and $\mathbf{C d}$ are the category priority scores generated using AHP based on the preference scores entered by the RPA adopter. The subscripts $\mathbf{g}, \mathbf{i}, \mathbf{p}$ and $\mathbf{d}$ denotes the categories Game Changer, Influencer, Persuader and Dissuader respectively.

Step 3: RPA adopter gives preference score to each of the features under a category to generate a priority score of the features using AHP.

Example: If category ' $\mathrm{G}$ ' has 5 features, preference scores will be given to each one of them. Then, based on AHP calculations, the model generates priority scores $\mathbf{G} \mathbf{j}$ for $\mathbf{j}=\mathbf{1 , 2 , 3 , 4 , 5}$ where $\mathbf{j}$ is the number of features in the category.

Step 4: Analyse each of the shortlisted RPA vendor and count the number of features corresponding to each category. Note that for category $\mathrm{P}$ and $\mathrm{D}$ matching does not apply as they consist of previously unconsidered features. Hence, these features can only be categorised into $\mathrm{P}$ and D. Also, post categorisation, step 3 needs to be repeated for category $\mathrm{P}$ and $\mathrm{D}$ features to find their priority scores.

Example: Ngk - Number of features matching into $\mathrm{G}$ category for the kth RPA vendor

Npk - Number of features categorized into P category for the kth RPA vendor

Step 5: Calculate the Revised Category Priority Score (Rgk,Rik,Rpk,Rdk) by multiplying the category priority scores with the number of matching features of that category of every RPA vendor.

Example: Let $\mathrm{Ngk}=3$, then $\mathbf{R g k}=\mathrm{Ngk} \times \mathrm{Cg}$

Step 6: For each RPA vendor, category-wise find the aggregate feature priority score (Agk, Aik,
Apk, Adk) based only on the features present. This calculation is based on the type of category. It has been discussed more in detail in section 3.2.3.

Step 7: For each RPA vendor, now multiply the Revised Category Priority Score with the Aggregate feature priority score to get categorywise final priority score for each RPA vendor.

Example: Final category $\mathrm{G}$ priority score for vendor ' $\mathrm{k}$ ' is

Fgk $=$ Rgk $x$ Agk

Step 8: For each RPA vendor calculate the final score by taking sum total of all the final category scores

Example: Final score for vendor ' $\mathrm{k}$ ' is $\mathbf{V k}=\mathrm{Fgk}$ + Fik + Fpk + Fdk

Based on the highest score, the RPA vendor can be selected for implementing the project of RPA adoption in the Organization.

\subsection{Model Demonstration}

To demonstrate the designed model properly, we need to first establish a premise or scenario and then proceed. So, we are first going to establish the context by taking up a pseudo RPA adopting organization, then do feature identification and categorization based on some corporate literature since RPA implementation is very much a concept discussed more in businesses rather than in academia.

\subsubsection{Premise for Demonstration}

Let us consider a pseudo RPA adopting organisation AB Pvt. Ltd. The management of this organisation had decided to create a Centre of Excellence (COE) for the diagnostic study and research of this implementation. After the complete analysis was done, RPA implementation work was to be started. The RPA vendor had to be selected for the same.

The COE had done a market study of the existing research and had shortlisted 3 RPA vendors who could be considered for the evaluation. These are RPA Vendor 1, RPA Vendor 2, RPA Vendor 3, and RPA Vendor 4.

Now, the evaluation process was to begin. 


\subsubsection{Criteria selected based on literature from recent corporate research and reports}

The features identified have been categorized into category $\mathrm{G}$ features have been named as $\mathrm{G} 1, \mathrm{G} 2$, G3, G4 and G5 and category I features have been named as I1, I2, I3. (Shown in Table 3)

$\mathrm{G}$ (Game Changer) and I (Influencer). The

\begin{tabular}{|l|l|c|l|}
\hline \multicolumn{2}{|c|}{ Game Changer (G) } & \multicolumn{2}{c|}{ Influencer (I) } \\
\hline G1 & Run on a virtualized server & I1 & Support Ul automation \\
\hline G2 & Support process discovery & I2 & Assist in testing and debugging the automation during development \\
\hline G3 & Built-in OCR capability & I3 & prepackaged adapters for various cloud services \\
\hline G4 & Have recorders & & \\
\hline
\end{tabular}

Table 3 - Categorization of identified features

Now that the categorization is done, we shall move on to the quantitative calculation part of the model and demonstrate the vendor score calculation.

\subsubsection{Demonstration of the calculation of vendor score}

Let us recall the steps as explained in Section 3.1.4. The Step 1 is already done, that is the identification of features and its categorization.

\section{Step 2}

Categorization is already done. Preference score to be assigned for the categories to get their priority scores.

\begin{tabular}{|c|c|c|c|c||}
\hline Preference Score & G & I & P & D \\
\hline G & $\mathbf{l}$ & 3 & 5 & 7 \\
\hline I & 0.333333333 & $\mathbf{l}$ & 3 & 3 \\
\hline P & 0.2 & 0.333333333 & $\mathbf{l}$ & 3 \\
\hline D & 0.142857143 & 0.333333333 & 0.333333333 & $\mathbf{1}$ \\
\hline
\end{tabular}

\begin{tabular}{|c|c|}
\hline Category & Priority Score \\
\hline $\mathbf{C g}$ & 0.591720779 \\
\hline $\mathbf{C i}$ & 0.244859307 \\
\hline $\mathbf{C p}$ & 0.099296537 \\
\hline $\mathrm{Cd}$ & 0.064123377 \\
\hline \hline
\end{tabular}

Table 4 - Assigned preference score (left) and Priority Scores (right) for the Categories

Step 3

Preference score to be assigned for the features of each categories to get their priority scores.

\begin{tabular}{|c|c|c|c|c|}
\hline Feature Scoring & G1 & G2 & G3 & G4 \\
\hline G1 & $\mathbf{1}$ & 3 & 5 & 7 \\
\hline G2 & 0.3333333 & $\mathbf{1}$ & 5 & 7 \\
\hline G3 & 0.2 & 0.2 & $\mathbf{1}$ & 3 \\
\hline G4 & 0.1428571 & 0.1428571 & 0.3333333 & $\mathbf{1}$ \\
\hline
\end{tabular}

\begin{tabular}{|c|c|}
\hline Feature & Priority Score \\
\hline G1 & 0.529361436 \\
\hline G2 & 0.314798038 \\
\hline G3 & 0.105068194 \\
\hline G4 & 0.050772332 \\
\hline
\end{tabular}

Table 5- Assigned preference score (left) and Priority Scores (right) for G features

\begin{tabular}{|c|c|c|c|c|c||}
\hline Feature Scoring & I1 & I2 & I3 & I4 & I5 \\
\hline I1 & $\mathbf{1}$ & 3 & 5 & 7 & 9 \\
\hline I2 & 0.3333333 & $\mathbf{1}$ & 3 & 5 & 9 \\
\hline I3 & 0.2 & 0.3333333 & $\mathbf{1}$ & 3 & 5 \\
\hline I4 & 0.1428571 & 0.2 & 0.333333333 & $\mathbf{1}$ & 3 \\
\hline I5 & 0.1111111 & 0.1111111 & 0.2 & 0.3333333 & $\mathbf{1}$ \\
\hline
\end{tabular}

\begin{tabular}{|c|c|}
\hline Feature & Priority Score \\
\hline I1 & 0.498363193 \\
\hline I2 & 0.255654914 \\
\hline I3 & 0.118059861 \\
\hline I4 & 0.054795169 \\
\hline I5 & 0.031869398 \\
\hline
\end{tabular}

Table 6- Assigned preference score (left) and Priority Scores (right) for I features

\section{Step 4}

Analyse each of the shortlisted RPA vendor and count the number of features corresponding to each category. The additional features that were not considered are categorized into P (Persuader) and D (Dissuader). Step 3 has to be repeated for these new features to get their priority scores.
Table 7 shows the count of matched features per category for each vendor and the details of the matching features. Also, Table 8 provides a reference for identifying the $\mathrm{P}$ and $\mathrm{D}$ features vendor-wise. Table $9 \& 10$ has the priority scores of the category $\mathrm{P}$ and $\mathrm{D}$ features respectively. 


\begin{tabular}{|c|c|c|c|c|}
\hline Vendor & $\mathrm{G}(\mathrm{Ngk})$ & $\mathrm{I}(\mathrm{Nik})$ & $\mathrm{P}(\mathrm{Npk})$ & $\mathrm{D}(\mathrm{Ndk})$ \\
\hline RPA Vendor $1(\mathrm{k}=1)$ & 2 & 4 & 1 & 3 \\
\hline RPA Vendor $2(\mathrm{k}=2)$ & 4 & 2 & 0 & 1 \\
\hline RPA Vendor $3(\mathrm{k}=3)$ & 0 & 2 & 3 & 0 \\
\hline RPA Vendor $4(\mathrm{k}=4)$ & 3 & 0 & 2 & 1 \\
\hline
\end{tabular}

\begin{tabular}{|c|c|c|c|c|}
\hline Vendor & G & I & P & D \\
\hline RPA Vendor 1 & $G 1,2$ & $11,2,3,4$ & P1 & $\mathrm{D} 1,2,3$ \\
\hline RPA Vendor 2 & $\mathrm{G} 1,2,3,4$ & 11,2 & & $\mathrm{D} 2$ \\
\hline RPA Vendor 3 & & 11,2 & $\mathrm{P} 1,2,3$ & \\
\hline RPA Vendor 4 & $\mathrm{G1} 2,3$ & & $\mathrm{P} 1,2$ & $\mathrm{D} 3$ \\
\hline
\end{tabular}

Table 7- Count of matched features (left) and details (right)

\begin{tabular}{|c|l|}
\hline Identity & \multicolumn{1}{|c|}{ Feature } \\
\hline P1 & Solution integrates a natural language processing engine \\
\hline P2 & Supports changes to a deployed automation \\
\hline P3 & Business continuity and DR features \\
\hline D1 & Store user Ds and passwords \\
\hline D2 & Auto cleaning of history \\
\hline D3 & Dedicated version-control system \\
\hline
\end{tabular}

Table 8 - Reference list for persuaders (P) and dissuaders (D)

\begin{tabular}{|c|c|c|c||}
\hline Feature Scoring & P1 & P2 & P3 \\
\hline P1 & $\mathbf{1}$ & 3 & 7 \\
\hline P2 & 0.3333333 & $\mathbf{1}$ & 5 \\
\hline P3 & 0.1428571 & 0.2 & $\mathbf{1}$ \\
\hline
\end{tabular}

\begin{tabular}{|c|c|}
\hline Feature & Priority Score \\
\hline P1 & 0.643388869 \\
\hline P2 & 0.282839025 \\
\hline P3 & 0.073772106 \\
\hline
\end{tabular}

Table 9- Assigned preference score (left) and Priority Scores (right) for P features

\begin{tabular}{|c|c|c|c|}
\hline Feature Scoring & D1 & D2 & D3 \\
\hline D1 & $\mathbf{1}$ & 3 & 5 \\
\hline D2 & 0.3333333 & $\mathbf{1}$ & 3 \\
\hline D3 & 0.2 & 0.3333333 & $\mathbf{1}$ \\
\hline
\end{tabular}

\begin{tabular}{|c|r|}
\hline Feature & Priority Score \\
\hline P1 & 0.643388869 \\
\hline P2 & 0.282839025 \\
\hline P3 & 0.073772106 \\
\hline
\end{tabular}

Table 10 - Assigned preference score (left) and Priority Scores (right) for D features

Step 5

Calculate Revised Priority Score for every category based on the count of features matching for the category per vendor.

\begin{tabular}{|c|c|c|c|c|c|}
\hline & $\mathrm{Cg}$ & $\mathrm{Ci}$ & Cp & Cd & \multirow{7}{*}{$\begin{array}{l}\text { Cd is converted } \\
\text { to negative to } \\
\text { signify that its } \\
\text { presence is } \\
\text { undesirable }\end{array}$} \\
\hline Weight & 0.59172 & 0.24486 & 0.0993 & -0.0641 & \\
\hline Frequency & Ngk & Nik & Npk & Ndk & \\
\hline RPA Vendor $1(\mathrm{k}=1)$ & 2 & 4 & 1 & 3 & \\
\hline RPA Vendor $2(k=2)$ & 4 & 2 & $\mathbf{0}$ & 1 & \\
\hline RPA Vendor $3(k=3)$ & $\mathbf{0}$ & 2 & 3 & $\mathbf{0}$ & \\
\hline RPA Vendor $4(k=4)$ & 3 & $\mathbf{0}$ & 2 & 1 & \\
\hline Revised Priority Score & Rgk & Rik & Rpk & Rdk & \multirow{5}{*}{$\begin{array}{l}\mathbf{R} \mathbf{g k}=\mathbf{C g} \mathbf{~} \mathbf{N} \mathbf{g k} \\
k=1 \text { to } 4\end{array}$} \\
\hline RPA Vendor $1(k=1)$ & 1.18344 & 0.97944 & 0.0993 & -0.1924 & \\
\hline RPA Vendor $2(k=2)$ & 2.36688 & 0.48972 & $\mathbf{0}$ & -0.0641 & \\
\hline RPA Vendor $3(k=3)$ & $\mathbf{0}$ & 0.48972 & 0.29789 & $\mathbf{0}$ & \\
\hline RPA Vendor $4(k=4)$ & 1.77516 & $\mathbf{0}$ & 0.19859 & -0.0641 & \\
\hline
\end{tabular}

Table 11- Calculated Revised Priority Score

\section{Step 6}

For each RPA Vendor, based on the features present and absent, an aggregate score is calculated.

\section{Example:}

Given below, in case of RPA Vendor 1 the following features are present and absent:
G(Present):
G1
and
G2

G(Absent): G3 and G4

I (Present): I1, I2, I3 and I4

I (Absent): I5 
P(Present):

P (Absent): Not Applicable

D(Present): D1, D2and D3

D (Absent): Not Applicable

- $\quad$ Ag1 = 1-( G3+G4); Since the absence of $\mathrm{G}$ feature disappoints the RPA adopter

- $\mathbf{A i 1}=(\mathbf{I} 1+\mathbf{I} 2+\mathbf{I 3 + I 4}) ;$ As the vendor score should improve with presence of these features

\begin{tabular}{|l|c|c|c|c|}
\hline Feature Aggregate & Agk & Aik & Apk & Adk \\
\hline RPA Vendor $\mathbf{1}(\mathbf{k}=\mathbf{1})$ & 0.844159 & 0.926873 & 0.643389 & 1 \\
\hline RPA Vendor 2 (k=2) & 1 & 0.754018 & 0 & 0.260498 \\
\hline RPA Vendor 3 (k=3) & 0 & 0.754018 & 1 & 0 \\
\hline RPA Vendor 4 (k=4) & 0.949228 & & 0.717161 & 0.106156 \\
\hline
\end{tabular}

Table 12- Calculated Aggregate Feature Score

feature priority score to get category-wise final priority score for each RPA vendor.

\section{Step 7}

For each RPA vendor, now multiplied the Revised

Category Priority Score with the Aggregate

\begin{tabular}{|l|c|c|c|c|} 
Feature Aggregate & Agk & Aik & Apk & Adk \\
\hline RPA Vendor $\mathbf{1}(\mathbf{k}=\mathbf{1})$ & 0.844159 & 0.926873 & 0.643389 & 1 \\
\hline RPA Vendor 2 (k=2) & 1 & 0.754018 & 0 & 0.260498 \\
\hline RPA Vendor 3 (k=3) & 0 & 0.754018 & 1 & 0 \\
\hline RPA Vendor 4 (k=4) & 0.949228 & & 0.717161 & 0.106156 \\
\hline Revised Priority Score & Rgk & Rik & Rpk & Rdk \\
\hline RPA Vendor 1 (k=1) & 1.183442 & 0.979437 & 0.099297 & -0.19237 \\
\hline RPA Vendor 2 (k=2) & 2.366883 & 0.489719 & 0 & -0.06412 \\
\hline RPA Vendor 3 (k=3) & 0 & 0.489719 & 0.29789 & 0 \\
\hline RPA Vendor 4 (k=4) & 1.775162 & 0 & 0.198593 & -0.06412 \\
\hline Final Category-wise Score & Fgk & Fik & Fpk & Fdk \\
\hline RPA Vendor 1 (k=1) & 0.999013 & 0.907814 & 0.063886 & -0.19237 \\
\hline RPA Vendor 2 (k=2) & 2.366883 & 0.369257 & 0 & -0.0167 \\
\hline RPA Vendor 3 (k=3) & 0 & 0.369257 & 0.29789 & 0 \\
\hline RPA Vendor 4 (k=4) & 1.685033 & 0 & 0.142423 & -0.00681 \\
\hline
\end{tabular}

Table 13- Category-wise final scores for each RPA vendor

For each RPA vendor, calculated net score by taking sum of final scores across categories.

Step 8

\begin{tabular}{|l|c|}
\hline Vendor Name & Vendor Score $(\mathbf{V k})$ \\
\hline RPA Vendor $\mathbf{1}(\mathbf{k}=\mathbf{1})$ & 1.778343618 \\
\hline RPA Vendor $\mathbf{2}(\mathbf{k}=\mathbf{2})$ & $\mathbf{2 . 7 1 9 4 3 5 8 1 1}$ \\
\hline RPA Vendor $\mathbf{3}(\mathrm{k}=\mathbf{3})$ & 0.667146313 \\
\hline RPA Vendor $\mathbf{4}(\mathbf{k}=\mathbf{4})$ & 1.820649306 \\
\hline
\end{tabular}

Table 14-Final scores for each RPA vendor

We can observe that RPA Vendor 2 is leading with a score of approximately 2.72.
Results and Discussions

We can observe in section 3.2.3 that by step 8, the final vendor scores are available to us. So, we can select the vendor accordingly. 
It is recommended that the RPA adopter selects the highest scoring vendor because the scoring mechanism is transparent and extensively based on the initial preferences of the RPA adopter. However, the Organization may choose to go with the second best in case of any special scenario which could not fit into this model.

As mentioned earlier, it is highly essential that the preferences are clearly identified and stated by the RPA adopter. Also, the scoring has to follow the Saatys scale and be consistent. This will be ensured through the conventional AHP calculation, that is by checking the Consistency Ratio (CR) which needs to be less than or equal to 0.1 in order to be consistent.

\section{Conclusion}

In this paper an evaluation model for RPA vendors has been developed by taking references from the Kano Model and Analytic Hierarchy Process. Both the models being versatile and usable in diverse areas of manufacturing and service industry, provided the perfect blend to our model. While Kano Model was used to develop the qualitative part of the model, like categorization of requirements into appropriate brackets and assessing RPA vendors for the presence or absence of the requirements, AHP proved to be a powerful tool is assigning preference scores to each of the categories and requirements so that we get a ranking of the RPA vendors based on the aggregate weightage of each requirement across all the categories.

The flexibility of this model lies in the fact that, each new RPA adopter can assign different priorities to the categories and requirements to take the decision accordingly. This make the model suitable for any industry opting for RPA adoption.

Another advantage of this paper is the fact that it could be extended to be used for any kind of supplier evaluation. Keeping in mind that there are many established methodologies to evaluate suppliers of physical goods, it is best left to the discretion of manufacturing organizations whether or not they wish to adopt this model. However, for any organization primarily targeting best fit RPA vendor for their well-planned RPA implementation project, can definitely use this standard yet tailored model.

\section{References}

[1] AIMultiple. (2020). RPA Ecosystem : Companies that enable RPA [ 2020 update ]. $1-9$.

[2] Asif, M. (2015). A critical review of service excellence models: towards developing an integrated framework. Quality and Quantity, 49(2),

763-783. https://doi.org/10.1007/s11135-014-0022-y

[3] Baffoe, G. (2019). Exploring the utility of Analytic Hierarchy Process (AHP) in ranking livelihood activities for effective and sustainable rural development interventions in developing countries. Evaluation and Program Planning, 72(March 2018), 197-204. https://doi.org/10.1016/j.evalprogplan.2018. 10.017

[4] Büyüközkan, G. (2012). An integrated fuzzy multi-criteria group decision-making approach for green supplier evaluation. International Journal of Production Research, 50(11), 2892-2909. https://doi.org/10.1080/00207543.2011.564 668

[5] Bygstad, B. (2017). Generative innovation: A comparison of lightweight and heavyweight IT. Journal of Information Technology, 32(2), 180-193. https://doi.org/10.1057/jit.2016.15

[6] Chambers, D., Coronado, G., Green, B., Jarvik, J., Septimus, E., Tuzzio, L., \& Zatzick, D. (2017). Key Considerations. The Living https://doi.org/10.28929/050

[7] Chen, M. C., Hsu, C. L., \& Lee, L. H. (2020). Investigating pharmaceutical logistics service quality with refined Kano's model. Journal of Retailing and Consumer Services, 57, 1-2. https://doi.org/10.1016/j.jretconser.2020.102 231

[8] Dickson, G. W. (1966). An Analysis Of Vendor Selection Systems And Decisions. Journal of Purchasing, 2(1), 5-17. https://doi.org/10.1111/j.1745493x.1966.tb00818.x 
[9] Firat, S. Ü. O., Akan, M. Ö. A., Ersoy, E., Gök, S., \& Ünal, U. (2017). A six sigma DMAIC process for supplier performance evaluation using AHP and Kano's model. International Journal of Business Analytics, 4(2), 37-61. https://doi.org/10.4018/IJBAN.2017040103

[10] Ghorabaee, M. K., Amiri, M., Zavadskas, E. K., \& Antucheviciene, J. (2017). Supplier evaluation and selection in fuzzy environments: A review of MADM approaches. Economic ResearchEkonomska Istrazivanja , 30(1), 1073-1118. https://doi.org/10.1080/1331677X.2017.131 4828

[11] Gould, R. (2018). Robotic Process Automation (RPA): Past, Present and Future | Kofax. Kofax, box 1, 1-5. https://www.kofax.com/Blog/2018/august/r obotic-process-automation-rpa-past-presentand-future

[12] Gurwitz, C. (2020). WHAT WE DO PRODUCTS WHAT THEY SAY Leveraging RPA for COVID-19 challenges. $1-6$.

[13] Ho, W., Xu, X., \& Dey, P. K. (2010). Multi-criteria decision making approaches for supplier evaluation and selection: A literature review. European Journal of Operational Research, 202(1), 16-24. https://doi.org/10.1016/j.ejor.2009.05.009

[14] Improta, G., Perrone, A., Russo, M. A., \& Triassi, M. (2019). Health technology assessment (HTA) of optoelectronic biosensors for oncology by analytic hierarchy process (AHP) and Likert scale. BMC Medical Research Methodology, 19(1), 1-14. https://doi.org/10.1186/s12874019-0775-z

[15] Ivlev, I., Kneppo, P., \& Bartak, M. (2014). Multicriteria decision analysis: a multifaceted approach to medical equipment management. Technological and Economic Development of Economy, 20(3), 576-589. https://doi.org/10.3846/20294913.2014.943 333

[16] Le Clair, C., Cullen, A., \& King, M. (2017). The forrester wave TM: Robotic process Automation- the 12 providers that matter most and how they stack up. Forrester, 1-19. http://www.bluvaultsolutions.com/wpcontent/uploads/2017/11/Robotics.pdf

[17] Materla, T., Cudney, E. A., \& Hopen, D. (2019). Evaluating factors affecting patient satisfaction using the Kano model. International Journal of Health Care Quality Assurance, 32(1), 137-151. https://doi.org/10.1108/IJHCQA-02-20180056

[18] Matzler, K., Bailom, F., Sauerwein, E., \& Hinterhuber, H. H. (1996). How to delight your customers. Journal of Product \& Brand Management, 5(2), 6-18. https://doi.org/10.1108/1061042961011946 9

[19] Naved Rashid, Cathy Tornbohm, S. R. I. (2020). How to Select the Right RPA Service Provider to Achieve Success Strategic Planning Assumption ( $\mathrm{s}$ ). February, 1-10.

[20] Noppen, P. (2019). The Qualitative Impact of Robotic Process Automation.

[21] Pesonen, M., Kurttila, M., Kangas, J., Kajanus, M., \& Heinonen, P. (2001). Assessing the priorities using A'WOT among resource management strategies at the Finnish Forest and Park Service. Forest Science, 47(4), 534-541. https://doi.org/10.1093/forestscience/47.4.5 34

[22] Ray, S., Villa, A., Tornbohm, C., Rashid, N., \& Alexander, M. (2020). Magic Quadrant for Robotic Process Automation. Gartner, 1-40. https://www.gartner.com/doc/reprints?id=11ZK435W1\&ct=200728\&st=sb\&mkt_tok=e yJpIjoiWVdVeE5ESm1NakJoWXpKayIsIn QiOiJiSWtLQUtqS1laSG82Y0ZBdENcLzF BbGRUWnlScnVLc25kSTFWZWNHXC80 dnNjcU16bWVXbVM2b3pxVnVOaUZaQT JQWIUxdTZpWjBOTIVUSE1sdmRueFZS QjVTWms5OXNENjF2a3cyc1Zz

[23] Scheppler, B., \& Weber, C. (2020). Robotic Process Automation. In Informatik- 
Spektrum (Vol. 43, Issue 2). https://doi.org/10.1007/s00287-020-01263-6

[24] Shokouhyar, S., Shokoohyar, S., \& Safari, S. (2020). Research on the influence of after-sales service quality factors on customer satisfaction. Journal of Retailing and Consumer Services, 56(March), 102139.

https://doi.org/10.1016/j.jretconser.2020.102 139

[25] Singh, R., Avikal, S., Rashmi, R., \& Ram, M. (2020). A Kano model, AHP and TOPSIS based approach for selecting the best mobile phone under a fuzzy environment. International Journal of Quality and Reliability Management, Mcdm. https://doi.org/10.1108/IJQRM-012020-0022

[26] Srivastava, S. (2020). RPA PREDICTION 2020 : HOW COVID-19 WILL TRANSFORM THE AUTOMATION LANDSCAPE ? 19-21.

[27] Sunil Kumar, C. V., \& Routroy, S. (2017). Analysis of suppliers' preferences to a manufacturer using Kano model and performance value analysis. 11(1-2), 6-27. https://doi.org/10.1504/IJBSR.2017.080831

[28] Syed, R., Suriadi, S., Adams, M., Bandara, W., Leemans, S. J. J., Ouyang, C., ter Hofstede, A. H. M., van de Weerd, I., Wynn, M. T., \& Reijers, H. A. (2020). Robotic Process Automation: Contemporary themes and challenges. Computers in Industry, 115 , 103162. https://doi.org/10.1016/j.compind.2019.103 162

[29] Taherdoost, H., \& Brard, A. (2019). Analyzing the Process of Supplier Selection Criteria and Methods. Procedia Manufacturing, 32, 1024-1034. https://doi.org/10.1016/j.promfg.2019.02.31 7

[30] Weber, C. A., Current, J. R., \& Benton, W. C. (1991). Vendor selection criteria and methods. European Journal of Operational Research, 50(1), 2-18. https://doi.org/10.1016/03772217(91)90033-R
[31] Willcocks, L. (2020). Robo-Apocalypse cancelled? Reframing the automation and future of work debate. Journal of Information Technology, 2016. https://doi.org/10.1177/0268396220925830

[32] Wong, A. T.-T., \& Ho, M. W.-M. (2019). Service Quality and Customer Satisfaction on Budget Airlines: Kano Model Approach. Journal of Economics, Management and Trade, 24(5), 1-16. https://doi.org/10.9734/jemt/2019/v24i5301 78

[33] Xie, M. (2020). CXO Surveys : IT and Digital Transformation Show Growing Value as the COVID - 19 Epidemic Takes its Toll. 